\title{
ESTRUTURAÇÃO E ADEQUAÇÃO DE ÓRGÃO MUNICIPAL DE PROTEÇÃO E DEFESA CIVIL: COMENTÁRIOS À LEI No 5.144/2016 DO MUNICÍPIO DE TAUBATÉ/SP
}

\section{STRUCTURE AND ADEQUACY OF CIVIL PROTECTION MUNICIPAL AUTHORITY: COMMENTS TO MUNICIPAL LAW №5144/2016 OF TAUBATÉ, SÃO PAULO}

\author{
Patrícia Nunes Lima Bianchi ${ }^{1}$ João \\ Carlos Valentim Veiga Junior ${ }^{2}$
}

\begin{abstract}
Resumo
Este trabalho tem por objetivo analisar a estruturação e adequação da Coordenadoria Municipal de Proteção e Defesa Civil (COORDEC) do Município de Taubaté/SP em relação à Política Nacional de Proteção e Defesa Civil. Trata-se de estudo descritivo, com abordagem qualitativa, onde se analisará a legislação municipal que aborda a temática da proteção e defesa civil. Para tanto, divide-se em três partes. Inicialmente, aborda-se, em termos gerais, o histórico da proteção e defesa civil no Brasil, abordando inclusive a mudança de paradigma ocorrida depois dos anos 1990. Em segunda etapa, verifica-se como o Município de Taubaté/SP estruturou seu órgão municipal de defesa civil ao longo dos anos. Analisar-se-á a Lei Municipal no 5.144/2016, focando nos artigos que criam a Coordenadoria Municipal de Proteção e Defesa Civil do Município de Taubaté/SP. Por fim, verificar-se-á se a legislação municipal atende aos princípios da proteção e defesa civil dispostos na Política Nacional que cuida da matéria.
\end{abstract}

Palavras-chave: Proteção e Defesa Civil; Administração Pública; Estrutura governamental; Comentários à legislação municipal.

\begin{abstract}
This paper aims to analyze the structure and adequacy of the Civil Protection Municipal Authority (COORDEC) in the city of Taubaté, State of São Paulo, in relation to the Brazilian Civil Protection's Policy. This is a descritive study with qualitative approach, which will analyze the municipal law that deals with the civil protection. Therefore, it is divided into three parts. Initially, we discuss, in general terms, the history of the civil protection in Brazil, including the change of paradigm that occurred after de 1990s. In the second stage, it is verified how the city of Taubaté structured its municipal agency of civil protection over the years. After, it will analyze the Municipal Law № 5144/2016, responsible for creating the Civil Protection Coordination. Finally, it will be examined on determine whether municipal legislation complies with the principles of protection and civil defense prepared by the National Policy that takes care of the matter.
\end{abstract}

Keywords: Civil Protection; Civil Defence; government; governmental structure; comments to local law.

\footnotetext{
${ }^{1}$ Doutora em Direito pela Universidade Federal de Santa Catarina (UFSC). Docente e Pesquisadora da Graduação e do Programa de Mestrado em Direito do Centro Universitário Salesiano de São Paulo (UNISAL). E-mail: patricianbianchi@gmail.com

2 Mestrando em Direito pelo Centro Universitário Salesiano de São Paulo (UNISAL). Membro da Rede Nacional de Emergência de Radioamadores da Secretaria Nacional de Proteção e Defesa Civil do Ministério da Integração Nacional (RENER/SEDEC/MI). Secretário Executivo do Conselho Municipal de Proteção e Defesa Civil de Taubaté/SP. E-mail: veiga.junior@live.com
} 


\section{INTRODUÇÃO}

Desde 2012, com a aprovação da nova versão da Política Nacional de Proteção e Defesa Civil, os municípios são demandados a atualizarem sua legislação que aborde a matéria.

Em São Paulo, por exemplo, a Coordenadoria Estadual de Defesa Civil incentiva a capacitação constante de agentes municipais, por meio de sua Divisão de Planejamento, Legislação e Ensino (DIPLEN), que realiza oficinas regionais voltadas à atuação em períodos de chuvas intensas ou de estiagem, bem como a reestruturação organizacional, das antigas Comissões de Defesa Civil (COMDEC) para Coordenadorias de Proteção e Defesa Civil, por meio de orientações aos municípos difundidas durante aquelas oficinas (SÃO PAULO, 2016; TEMPO AGORA, 2015; GAZETA, 2015).

Este artigo se divide em três partes: inicialmente, aborda-se a situação da Proteção e Defesa Civil em âmbito nacional, tratando-se de seu surgimento até a mudança de paradigma trazida pela Estratégia Internacional de Redução de Desastres. Em segunda etapa, delinear-se-á o Município de Taubaté/SP, caracterizando suscintamente a região onde se encontra, sua população e seu histórico legislativo na seara da proteção civil. Finalmente, tecer-se-ão comentários a mais recente legislação temática: a Lei no 5.144, de 12 de janeiro de 2016.

Salienta-se, desde já, que, no âmbito deste estudo, não há diferenciação entre Proteção Civil e Defesa Civil, já que, no Brasil, a atuação se dá de forma conjunta, por meio de seu sistema nacional.

Trata-se de estudo descritivo, com abordagem qualitativa, onde se analisará a legislação municipal que aborda a temática da proteção e defesa civil. Além disso, tem cunho bibliográfico, que não exaure os demais (LEITE, 1997), e documental, ao incluir a legislação (LAKATOS; MARCONI, 2012).

\section{A PROTEÇÃO CIVIL NO BRASIL}

A ideia de defesa divil, apesar de aparente novidade, remonta ao próprio surgimento dos grupos humanos, pois desde a Antiguidade, o homem já lutava por sua sobrevivência, num ambiente hostil (VEIGA JUNIOR, 2015; BRAUN, 2005), em que, inclusive, aperfeiçoaram suas técnicas protetivas frente aos rigores do clima (COTRIM, 2005).

Porém, sua concepção, enquanto instituição organizada e difundida junto às comunidades, sob o patrocínio do Estado, remonta ao período da Segunda Guerra (1939-1945), quando o risco de conflitos sobre parques industriais e cidades se sobrelevaram (VEIGA JUNIOR, 2015). 
Ainda em nível mundial, já se compreendia a necessidade de conviver com desastres naturais, de modo que, ao final da década de 1980, foi lançada a Década Internacional para a Redução de Desastres Naturais (1990-1999), pela Assembleia Geral das Nações Unidas (UN, 1989).

Resultaram deste período vários documentos que hoje são base para a Estratégia Internacional para a Redução de Desastres, tendo como principal mudança o paradigma da atuação (UNISDR, 2013).

Segundo o Corpo de Bombeiros Militar do Distrito Federal - CBMDF (2010), anteriormente os órgãos de proteção civil e os governos, como um todo, davam ênfase à resposta aos desastres, bem como à reabilitação dos cenários arruinados pelas catástrofes.

Porém, com a edição da Estratégia Internacional para Redução de Desastres, passou-se a incorporar a visão da prevenção e da preparação aos eventos que causassem qualquer adversidade. Tal fase se denomina "Gestão de Risco" (UFSC, 2013).

Nacionalmente, observa-se que, desde a Constituição Imperial de 1824, já havia a previsão do "socorro público" em caso de calamidades (UFSC, 2013), sendo que o entendimento, com o passar dos anos, foi se ampliando e passando a abarcar outras situações conforme o entendimento global de proteção e defesa civil ${ }^{3}$.

O país sempre sofreu com desastres dos mais variados tipos e magnitudes. Por exemplo, pode-se citar as enchentes que rotineiramente atingiam Porto Alegre, no Rio Grande do Sul, havendo registros datados de 1873, 1897 e 1941 (PORTO ALEGRE, 2014), ou as grandes secas nordestinas (FOLHA, 2012).

Tanto é que se observa uma alteração no que se pode nomear "percepção dos riscos" em nível constitucional, onde, a cada promulgação ou outorga de uma nova constituição, verificava-se a existência de dispositivos que previam a resposta aos desastres e assistência aos atingidos, sendo que, em 1967, já se trouxe a necessidade de se "organizar a defesa permanente" face aos eventos adversos.

\footnotetext{
${ }^{3}$ Em 1824, a Constituição Imperial previa exclusivamente os socorros públicos à população (BRASIL, 1824). Tal fato foi reprisado, de forma mais elaborada, na Constituição de 1891, em seu art. 5o, ao permitir que a União prestasse socorro ao Estado que, em caso de calamidade pública, solicitasse (BRASIL, 1891), sendo replicado de forma similar no art. 70, II, da subsequente (BRASIL, 1934). Já em 1946, a Carta impõe como dever da União o auxílio em calamidades, removendo a necessidade de solicitação de apoio pela unidade federativa, nos termos do art. 17, §2ㅇ (BRASIL, 1946). Contudo, por força do art. 8o XII, em 1967, visualiza-se pela primeira vez a ideia de prevenção aos desastres ao se abordar a organização permanente da defesa contra calamidades públicas, em especial a seca e inundações (BRASIL, 1967), que, na atual Constituição Cidadã, por meio de seu art. 21, XVIII, corresponde à competência da União em planejar e promover a defesa, de maneira permanente, contra as calamidades, com ênfase às secas e às inundações (BRASIL, 1988).
} 
Aliás, anota-se possível correlação entre tal dispositivo constitucional e a tragédia que se abateu sobre o Litoral Norte paulista em 1967, atingindo especialmente o município de Caraguatatuba, onde se registrou cerca de 400 mortos e milhares de desabrigados (CARAGUATATUBA, 2014).

Contudo, apesar da mudança da ênfase para a prevenção, em nível mundial, houve a necessidade de se incrementar ou fortalecer as comunidades locais, fato que se destacou sobremaneira após o tsunami que atingiu grande parte da Ásia em 2005.

$\mathrm{Na}$ esteira do referido tsunami, os Estados-membros da Organização das Nações Unidas elaboraram um documento intitulado Quadro de Ação de Hyogo, que se traduz como um instrumento para a implementação da redução do risco de desastres, editado em 2005 com visão de dez anos, objetivando aumentar a resiliência das comunidades locais, alcançando uma redução nas perdas humanas, materiais, econômicas e ambientais (UNISDR, 2007).

No Brasil, depois dos desastres que atingiram a Serra Fluminense no início de 2011, houve a edição da Política Nacional de Proteção e Defesa Civil, cujo marco legal é a Lei no 12.608, de 10 de abril de 2012 (BRASIL, 2012). Tamanho foi o impacto de tais eventos naquela ocasião que autores o nomearam "Megadesastre", conforme se aduz do excerto:

O Megadesastre da Região Serrana do estado do Rio de Janeiro ocorreu entre os dias 11 e 12 de Janeiro de 2011, atingindo sete cidades da região serrana do estado [...] e é considerado um dos maiores eventos de movimentos de massa generalizados do Brasil. Este evento, oficialmente, causou 947 mortes, com 300 desaparecimentos, mais de 50.000 desabrigados e afetando quase 1.000 .000 de pessoas (DOURADO; ARRAES; SILVA, 2012, p. 44, grifo nosso)

Ou seja, fez-se necessário um megadesastre para que se procedesse à revisão da da legislação temática, visto que, foi em decorrência deste momento, já em meados de 2012, que a "proteção" passou a figurar no ordenamento jurídico infraconstitucional, por meio da Lei no 12.608 anteriormente citada, trazendo oficialmente então os conceitos estabelecidos na Estratégia Internacional.

E é com base nessa Política que os municípios, devem atuar enquanto partes do Estado Federado, integrando o chamado Sistema Nacional de Proteção e Defesa Civil. Considerando que o Poder Público só pode fazer o que é previsto em lei, nos termos do artigo 37 da Constituição Federal de $1988^{4}$, os municípios foram demandados, ainda que indiretamente, a providenciarem a

\footnotetext{
${ }^{4}$ In verbis: "Art. 37. A administração pública direta e indireta de qualquer dos Poderes da União, dos Estados, do Distrito Federal e dos Municípios obedecerá aos princípios de legalidade, impessoalidade, moralidade, publicidade e eficiência [...]" (BRASIL, 1988).
} 
alteração nas respectivas legislações, para que passassem a prever a proteção de seus cidadãos.

\section{DEFESA CIVIL EM TAUBATÉ/SP}

O Município de Taubaté se localiza na Região Metropolitana do Vale do Paraíba, a cerca de 120 quilômetros a leste da capital paulista. Possui uma área de 625,92 km², inserindo-se na Bacia Hidrográfica do Rio Paraíba do Sul (BROLLO, 2012).

Segundo dados da Seade (2014; 2015), Taubaté conta com 293.782 habitantes, correspondendo à densidade demográfica de 470,05 habitantes por quilômetro quadrado, residindo sua população, em larga maioria, em áreas urbanizadas $(97,93 \%)$, o que se configura como acima da média regional $(94,3 \%)$ e estadual $(96,8 \%)$.

Há menção, no arcabouço jurídico municipal, à Comissão Municipal de Defesa Civil já pelos idos de 1983, por meio da Lei № 2.066, ao dispor sobre a chamada Campanha Permanente de Defesa Civil, onde o Executivo promoveria uma semana de atividades junto à população (TAUBATÉ, 1983). Contudo, nunca houve efetivamente a promoção de tal semana.

Em consulta ao sítio do Poder Legislativo, não há legislação anterior ao decreto de 1983. As referências à Defesa Civil no ordenamento jurídico municipal só retornam na década de 1990 (CÂMARA, 2016), quando, na Lei Orgânica do Município de Taubaté, expressa-se como competência do Município:

XXIII - criar a Comissão Municipal de Defesa Civil, com o objetivo de adotar medidas preventivas e recuperativas sobre eventos desastrosos, mediante 0 socorro às populações das áreas atingidas, visando à preservação da vida humana e ao restabelecimento do bem-estar (TAUBATÉ, 1990, p. 3).

Em 1993, foi reorganizado o Sistema Municipal de Defesa Civil, composto pela Comissão Municipal de Defesa Civil e por núcleos comunitários. Tal sistema é vinculado ao Sistema Estadual de Defesa Civil, por meio do Decreto no 7.286, de 19 de abril daquele ano (TAUBATÉ, 1993). Destaca-se que esse diploma legal vigorou até a recente promulgação da Lei no 5.144, já em 2016.

Por fim, observa-se que decorridos quase 4 (quatro) anos da Política Nacional de Proteção e Defesa Civil, se teve, em nível municipal, a entrada em vigor da nova legislação sobre a temática, que será abordada a seguir.

\section{COMENTÁRIOS À LEI MUNICIPAL № 5.144/2016}

A Lei no 5.144, de 12 de janeiro de 2016 é composta de 33 (trinta e três) artigos, divididos em três grandes áreas: a primeira se refere especificamente à Coordenadoria Municipal de 
Proteção e Defesa Civil; a segunda cuida do Conselho temático; e a terceira trata dos recursos e respectivo Fundo. Objeto deste artigo é apenas a primeira parte da legislação, composta por 15 (quinze) dispositivos.

Inicialmente, criou-se no município de Taubaté a Coordenadoria Municipal de Proteção e Defesa Civil, que recebeu a sigla de COORDEC após emenda durante sua tramitação junto ao Poder Legislativo. O artigo 10 da Lei no 5.144/2016 fixa que a COORDEC é "diretamente subordinada ao Chefe do Poder Executivo, com a finalidade de coordenar, em nível municipal, todas as ações de proteção e defesa civil, nos períodos de normalidade e anormalidade" (TAUBATÉ, 2016).

Nesses termos, competirá à COORDEC o desempenho das ações previstas na PNPDEC, quais sejam: a prevenção, preparação, mitigação, resposta e recuperação. Para tanto, deve-se subordinar, hierarquicamente, ao Prefeito Municipal, o que possibilitaria uma atuação mais célere, em casos de resposta. As atividades em si serão definidas mais adiante, quando da análise do artigo 5ㅇ.

Prevê o artigo 3 que a "COORDEC manterá com os demais órgãos congêneres municipais, estaduais e federais, estreito intercâmbio com o objetivo de receber e fornecer subsídios técnicos para esclarecimentos relativos à proteção de defesa civil". Tal dispositivo se soma ao 4을 artigo 5 , que vincula o órgão ora criado ao Sistema Nacional de Proteção e Defesa Civil, instituído pela Lei no 12.608/2012 (TAUBATÉ, 2016).

Com isso, reforça-se a Coordenadoria como a responsável pela gestão da proteção civil em nível municipal e também como o órgão que se ligará às demais defesas civis municipais, aos Sistemas estadual e nacional, visando seu próprio aperfeiçoamento ou dos demais, desde que esteja em busca de apoio técnico ou, sendo detentora desta mão de obra qualificada, possa dispor aos demais órgãos do Sistema.

O artigo 5 da Lei no 5.144/2016, por sua vez, estabelece em 18 incisos as atividades que passam a ser desempenhadas pela COORDEC. De modo genérico, quaisquer ações de proteção e defesa civil serão de responsabilidade da COORDEC, nos termos do art. 5ํ, I (TAUBATÉ, 2016). Porém, os demais incisos detalham algumas ações.

O inciso II do art. 50 (TAUBATÉ, 2016) especifica que todas as informações relativas a esta seara devem ser mantidas atualizadas e disponíveis. Há correlação entre este inciso e a Lei de Acesso à Informação (Lei no 12.527/2011), visto que qualquer informação deverá ser

\footnotetext{
5 In verbis: "Art. 40 A Coordenadoria Municipal de Proteção e Defesa Civil - COORDEC constitui órgão integrante do Sistema Nacional de Proteção e Defesa Civil - SINPDEC" (TAUBATÉ, 2016).
} 
disponibilizada à população, o que contribui com a cultura da percepção de riscos, já que a comunidade normalmente só compreenderá os riscos a que se sujeitam se conhecedora deles (UFSC, 2014).

Em seu terceiro inciso, o art. 50 (TAUBATÉ, 2016) fixa que a COORDEC é a responsável por elaborar e implementar planos, programas e projetos em sua área de atuação. Com isso, é possível efetivamente a criação de Planos Preventivos de Defesa Civil (PPDC), Planos de Atuação Emergencial (PAE), bem como projetos voltados à população, a exemplo dos "Agentes Mirins", "Defesa Civil na Escola" ou de capacitação para atuação em emergências para radioamadores. Também pode-se incluir aqui a gestão de programas habitacionais voltados à remoção de população em situação de risco.

O inciso IV do art. 5o da Lei no 5.144/2016 fixa como ação da COORDEC: "elaborar Plano de Ação Anual visando o atendimento das ações em tempo de normalidade, bem como, das ações emergenciais, com a garantia dos recursos no Orçamento Municipal" (TAUBATÉ, 2016). Esse plano de ação anual engloba a atuação em vistorias de campo, previsão de atividades preventivas junto à população, dentre outras medidas, que são postas à análise do Conselho Municipal de Proteção e Defesa Civil, como modo de accountability por força legal.

Recursos devem ser providos pelo Poder Executivo, sendo destinados preferencialmente ao Fundo temático. O inciso $V$, do 5o artigo, por sua vez, fixa que o Município, por meio da COORDEC, deve prever "recursos orçamentários próprios necessários às ações assistenciais de recuperação ou preventivas, como contrapartida às transferências de recursos da União" (TAUBATÉ, 2016). Isso posto, havendo a previsão orçamentária, evita-se que, em caso de necessidade, por conta da Lei de Responsabilidade Fiscal, seja preciso demandar o Poder Legislativo para suplementação de recursos, o que poderia prejudicar o desempenho das atividades da proteção civil.

Reforça tal entendimento a explanação de Moura (2016, p. 1.070), ao afirmar que:

A implementação das políticas públicas deve ocorrer mediante ações, programas e projetos adequados ao atendimento das prioridades - expressa nos objetivos e fins socialmente almejados - e às vinculações - estatuída na alocação e execução dos recursos públicos - traçados pela Constituição e pelos planos políticos nas respectivas leis materiais e formais.

Ou seja, por ser expressa em objetivos, sendo previstos recursos para execução de tais ações, transfigura-se a Lei no 5.144/2016 como uma formadora de política pública em matéria de proteção e defesa civil no Município de Taubaté. 
É de competência da COORDEC ainda a capacitação de recursos humanos para a realização de suas atividades, nos termos do inciso VI (TAUBATÉ, 2016). Essa capacitação se vincula, certamente, aos programas criados pelo órgão, conforme já abordado no inciso III do art. 5o da mesma Lei, já que o Executivo só pode realizar - com despesas - programas previstos em seu orçamento (BRASIL, 2000).

Também, prevê o art. 5o da Lei no 5.144/2016, em seu inciso VII, que a COORDEC deverá "manter o órgão central do SINPDEC informado sobre as ocorrências de desastres e atividades de Proteção e Defesa Civil" (TAUBATÉ, 2016). Essas informações, destinadas à Secretaria Nacional de Proteção e Defesa Civil do Ministério da Integração Nacional (Sedec/MI), são repassadas por meio do Sistema Integrado de Informações sobre Desastres - S2ID, por meio do qual registram-se ocorrências de grande vulto e acompanha-se os processos de reconhecimento federal de situações de anormalidade (situação de emergência ou estado de calamidade pública).

Ainda, a COORDEC será a responsável por propor ao Prefeito municipal a declaração dessas situações excepcionais, conforme dispõe o art. 5ㅇ, VIII (TAUBATÉ, 2016). Assim, por se tratar de órgão técnico, a ele compete verificar se o evento adverso ou desastre se enquadra no que dispõe a Instrução Normativa no 1/2012, do Ministério da Integração Nacional, que estabelece critérios para a decretação da situação de emergência ou do estado de calamidade pública.

Como órgão operacional, cabe à COORDEC também distribuir e controlar os suprimentos necessários em situações adversas, como define o art. 5o, IX (TAUBATÉ, 2016). Desta forma, sendo necessário distribuir itens de assistência humanitária, como alimentação e materiais de higiene pessoal, por exemplo, é de responsabilidade da Coordenadoria a administração do estoque, ainda que se utilize de servidores de outros setores do Poder Executivo municipal.

Já o inciso X, do 5o artigo da Lei no 5.144/2016, aborda a implantação de "banco de dados e elaborar os mapas temáticos sobre ameaças, vulnerabilidades e riscos de desastres" (TAUBATÉ, 2016). Ressalte-se que, atualmente, o Município de Taubaté dispõe de mapeamento de riscos publicado pelo Instituto Geológico paulista (BROLLO, 2012), contudo, é preciso manter mapeamentos diversos, incluindo riscos sobre parques industriais, acidentes envolvendo produtos perigosos, dentre outras que sejam de interesse da COORDEC.

“Promover campanhas públicas e educativas para estimular o envolvimento da população, motivando ações relacionadas com a proteção e defesa civil, através da mídia local" é o que especifica o inciso XII do art. 50 (TAUBATÉ, 2016). Além da previsão orçamentária, questão já abordada, com vistas à operacionalização de tais campanhas, a COORDEC pode se utilizar da 
estrutura fornecida pela própria Prefeitura, por meio de seu Departamento de Comunicação, devendo, para tanto, providenciar o material de divulgação e notas à imprensa, de modo que desperte nos órgãos da mídia local o interesse pela veiculação de notícias "preventivas", evitandose, sempre que possível, a mídia reativa.

O monitoramento e acompanhamento de informações de alerta de órgão de previsão do tempo visando a execução, em tempo hábil, dos planos operacionais, é tratado no art. 5o, XIII (TAUBATÉ, 2016). Hoje, tem-se fácil acesso a meios de monitoramento. Sítios eletrônicos como o do Centro de Previsão do Tempo e Estudos Climáticos do Instituto Nacional de Pesquisas Espaciais (CPTEC/Inpe), os radares da Rede de Meteorologia da Aeronática (Redemet) ou de empresas privadas (Climatempo, Somar Meteorologia, etc.) possibilitam aos agentes da COORDEC acompanhar o deslocamento de zonas de instabilidade que podem trazer eventos adversos (em especial tempestades convectivas) à sua área de atuação. Também, somam-se a estes a rede pluviométrica do Centro Nacional de Monitoramento e Alerta de Desastres do Ministério da Ciência, Tecnologia e Inovações e Comunicações (Cemaden/MCTIC) e do Instituto Nacional de Meteorologia (INMET).

Há também definição quanto à produção, manuseio ou transporte de produtos perigosos que exponham a risco a população, devendo tais procedimentos serem comunicados aos órgãos competentes, conforme dispõe o inciso XIV, art. 5o (TAUBATÉ, 2016). De posse do mapeamento de riscos associados a produtos perigosos elaborado com base no inciso $X$ do 5 ㅇ artigo da Lei $n$ 은 5.144/16, tais informações podem ser repassadas, por exemplo, à Companhia Ambiental do Estado (Cetesb) ou à Subcomissão de Estudos e Prevenção de Acidentes no Transporte Rodoviário de Produtos Perigosos da Região Metropolitana do Vale do Paraíba (criada em 2015 pela Secretaria Estadual de Logística e Transportes).

Além da atuação do funcionalismo municipal, pode-se agregar o voluntariado aos quadros da COORDEC, devendo ser implantados programas de capacitação para esse público, nos termos do art. 5, XV (TAUBATÉ, 2016). Preferencialmente, deve-se utilizar mão de obra já vinculada a organizações não governamentais, que preveem inclusive o fornecimento de seguro coletivo quando do desempenho de suas atividades. Com isso, respalda-se sobremaneira a presença do voluntariado junto à COORDEC.

Também é de responsabilidade da Coordenadoria Municipal de Proteção e Defesa Civil a implantação e manutenção do cadastro de recursos humanos, materiais e equipamentos a serem empregados em caso de eventos adversos, conforme estabelece o inciso XVI do art. 5o (TAUBATÉ, 
2016). Basicamente, essa atuação se traduz na aplicação do Sistema de Comando em Operações (SCO), conforme se vê:

Saber exatamente quantas pessoas estão envolvidas, onde elas estão trabalhando e o que estão fazendo, representa um fator importante de segurança. Além disso, um controle adequado da disponibilidade e emprego do pessoal envolvido da operação representa uma grande vantagem administrativa, sob a ótica da eficiência e eficácia gerencial (OLIVEIRA, 2009, p. 33)

Para compor tal cadastro, pode-se utilizar de formulário desenvolvido em arquivo Microsoft Excel ou similar, onde - em se tratando de recursos humanos - se estabelece uma sequência numérica, informando nome completo, endereço, telefone, instituição a que se vincula, se é voluntário e observações diversas. Referindo-se a recursos operacionais, também a ordem numérica; o tipo de recurso (trator, motosserra, ônibus, ambulância, etc); localização (pátio da Secretaria de Obras, hospital municipal, galpão, etc); instituição ou órgão a que pertence o recurso; nome, telefone e e-mail do responsável pela liberação; nome e contato dos operadores do recurso; e, por fim, a situação (se disponível, mobilizado ou indisponível). Durante o evento adverso, ou operação, encoraja-se a utilização de formulários do SCO, aplicando-se neste caso o formulário SCO-201, parte 9 - "Descrição dos recursos da operação".

O inciso XVII do artigo 5o da Lei em comento, por sua vez, prevê a possibilidade de intercâmbio com municípios irmanados, visando a troca de experiências que fortaleçam a atuação da COORDEC (TAUBATÉ, 2016). Não necessariamente tais municípios devam ser limítrofes. Assim, abre-se a oportunidade para contatar municípios de outros Estados, inclusive, ou países, desde que ampliada a experiência entre eles.

Por fim, o inciso XVIII do art. 5 trata da implantação de Núcleos Comunitários, em bairros e distritos (TAUBATÉ, 2016). A criação dos NUPDECs deve ser propiciada pela COORDEC, que providenciará a capacitação dos cidadãos, de forma que as discussões não se disvirtuem das finalidades do Núcleo Comunitário. Assim, questões não relacionadas à proteção e defesa civil são mais facilmente contidas, já que a população passa a compreender a função do órgão.

Findada a competência da Coordenadoria, o artigo 60 da Lei no 5.144/2016 trata da composição do órgão, dividindo-o em 5 (cinco) partes: Coordenador; Conselho; Secretaria Executiva; Setor de Prevenção de Desastres; e, Setor de Resposta a Desastres (TAUBATÉ, 2016).

De forma suscinta, fixa-se que o Coordenador será servidor municipal de carreira, a ser indicado pelo Prefeito, nos termos do art. 7으, tendo suas competências definidas no art. 8o, destacando-se, principalmente, que a ele cabe a direção e representação da Coordenadoria 
perante a sociedade. Portanto, o Coordenador é o responsável pelo gerenciamento das ações desenvolvidas pela COORDEC.

Subordinado ao Coordenador encontra-se a Secretaria Executiva, exercida por servidor efetivo, a quem cabe o suporte administrativo às ações da COORDEC, realizando especialmente o cadastro dos recursos humanos e operacionais, bem como atos de secretaria, gestão de recursos humanos, dentre outras atividades, nos termos dos artigos 9o e 10 da Lei no 5.144 (TAUBATÉ, 2016).

Também vinculado ao Coordenador, há o Setor de Prevenção de Desastres (art. 11), responsável, dentre outras ações, pelas campanhas públicas e educativas, monitoramento meteorológico e capacitação do voluntariado.

No mesmo nível hierárquico, o Setor de Resposta a Desastres (art. 12 da Lei no 5.144/2016) tem por atribuições "programar ações de medidas não-estruturais e medidas estruturais" bem como "executar a distribuição e o controle de suprimentos necessários em situações de desastres" (TAUBATÉ, 2016). Assim, este será o setor responsável pela logística humanitária, desde a verificação da necessidade (quantitativo de pessoas atingidas e itens a serem providenciados) até a efetiva distribuição.

Quanto ao Conselho, não será abordado neste estudo visto que se trata de um órgão consultivo e deliberativo com atribuições específicas que demandam análise em separado.

Destaca-se que a legislação previu ser permitido solicitar, de pessoas físicas e jurídicas, colaboração com objetivo de prevenir ou limitar riscos, perdas e danos que se sujeita a população, conforme dita o artigo 13 da Lei no 5.144/2016 (TAUBATÉ, 2016). Tal colaboração não substitui a requisição administrativa, prevista no artigo 5ㅇ, XXV, da Constituição Federal de 1988, que estabelece "no caso de iminente perigo público, a autoridade competente poderá usar de propriedade particular, assegurada ao proprietário indenização ulterior, se houver dano" (BRASIL, 1988). A colaboração se baseia na ideia de comunidade, em que os particulares dispõem de seus recursos voluntariamente, visando o bem-estar da sociedade.

Dispondo sobre a designação de servidores públicos para atuarem nas ações emergenciais, firmou-se, por meio do art. 14 da Lei no 5.144/2016, que desempenharão essas atividades sem prejuízo de suas funções, não fazendo jus a quaisquer gratificações ou remunerações (TAUBATÉ, 2016). A única exceção se refere à percepção de horas extraordinárias, de acordo com o Código de Administração Municipal. Independente da vantagem, o serviço será anotado no assentamento individual do servidor, já que é considerado relevante ao Município. 
Por fim, concluindo a parte legal que cabe à Coordenadoria Municipal de Proteção e Defesa Civil, tem-se, no artigo 15 da Lei no 5.144/16 que noções gerais sobre procedimentos de defesa civil devem constar dos currículos escolares nos estabelecimentos municipais de ensino (TAUBATÉ, 2016). Tais noções podem ser descentralizadas, em matérias que tenham reflexo nas ações de proteção e defesa civil como, por exemplo, Geografia, História, Física, dentre outras, onde o conteúdo programático seja aplicável ou próximo das atribuições da Defesa Civil.

\section{CONSIDERAÇÕES FINAIS}

A atualização da legislação municipal que aborda a temática da proteção e defesa civil ocorreu após quase quatro anos da entrada em vigor da Política Nacional correspondente.

Com tal lapso, foi possível ao Município de Taubaté conhecer quais elementos da legislação nacional seriam realmente aplicáveis em âmbito local e que, efetivamente, foram deixados pela União e Estado a seus cuidados.

Assim, grande parte das ações previstas na Lei № 5.144/2016 já eram oficiosas, ou seja, já eram desempenhadas pela Comissão Municipal de Defesa Civil em seu cotidiano.

Com a aprovação da nova legislação, tal Comissão foi substituída pela Coordenadoria Municipal de Proteção e Defesa Civil, composta exclusivamente por servidores municipais. Ainda que não estruturados em carreira própria (a COORDEC é composta por vários cargos, como braçais, escriturários, guardas civis, dentre outros), passou-se a ter definido em lei quais atribuições thes competem, dando respaldo às ações englobadas no ciclo de gestão de defesa civil.

Verifica-se ser adequada a estrutura dada pela legislação municipal ao órgão, vez que, em um município de quase 300.000 habitantes, a divisão da Coordenadoria em setores - a quem cabe determinadas tarefas - visa instrumentalizar as ações de proteção e defesa civil.

Também, a aproximação da comunidade, estabelecida em vários momentos como competência da COORDEC, respalda a atuação do órgão e coaduna com a cultura de percepção de riscos.

Por fim, conclui-se, então, que a Lei municipal no 5.144, de 12 de janeiro de 2016 está adequada aos preceitos e diretrizes da Política Nacional de Proteção e Defesa Civil.

\section{REFERÊNCIAS}

BRASIL. Constituição (1824). Disponível em: <http://www.planalto.gov.br/ccivil_03/Constituicao/Constituicao24.htm>. Acesso em 13 out. 2016. 
Constituição

(1891)

Disponível

em:

<http://www.planalto.gov.br/ccivil_03/Constituicao/Constituicao91.htm>. Acesso em 13 out. 2016. Constituição

(1934).

Disponível

em:

<http://www.planalto.gov.br/ccivil_03/Constituicao/Constituicao34.htm>. Acesso em 13 out. 2016. Constituição

(1946).

Disponível

em:

<http://www.planalto.gov.br/ccivil_03/Constituicao/Constituicao46.htm>. Acesso em 13 out. 2016. Constituição

(1967).

Disponível

em:

<http://www.planalto.gov.br/ccivil_03/Constituicao/Constituicao67.htm>. Acesso em 13 out. 2016. Constituição

(1988).

Disponível

em:

<http://www.planalto.gov.br/ccivil_03/constituicao/constituicaocompilado.htm>. Acesso em 20 jun. 2016.

Lei Complementar no 101, de 4 de maio de 2000. Estabelece normas de finanças públicas voltadas para a responsabilidade na gestão fiscal e dá outras providências. Disponível em: <http://www.planalto.gov.br/ccivil_03/leis/LCP/Lcp101.htm>. Acesso em: 20 jun. 2016.

Lei no 12.608, de 10 de abril de 2012. Institui a Política Nacional de Proteção e Defesa Civil PNPDEC; dispõe sobre o Sistema Nacional de Proteção e Defesa Civil - SINPDEC e o Conselho Nacional de Proteção e Defesa Civil - CONPDEC; autoriza a criação de sistema de informações e monitoramento de desastres; altera as Leis nos 12.340, de 1 - de dezembro de 2010, 10.257, de 10 de julho de 2001, 6.766, de 19 de dezembro de 1979, 8.239, de 4 de outubro de 1991, e 9.394, de 20 de dezembro de 1996; e dá outras providências. Disponível em: <http://www.planalto.gov.br/ccivil_03/_Ato2011-2014/2012/Lei/L12608.htm>. Acesso em: 20 jun. 2016.

Lei no 12.527, de 18 de novembro de 2011. Regula o acesso a informações previsto no inciso XXXIII do art. 5o, no inciso II do § 30 do art. 37 e no § 20 do art. 216 da Constituição Federal; altera a Lei no 8.112, de 11 de dezembro de 1990; revoga a Lei no 11.111, de 5 de maio de 2005, e dispositivos da Lei no 8.159, de 8 de janeiro de 1991; e dá outras providências. Disponível em: <http://www.planalto.gov.br/ccivil_03/_ato2011-2014/2011/lei/l12527.htm>. Acesso em: 20 jun. 2016.

BRAUN, Armin Augusto. Curso Básico de Defesa Civil. Coordenadoria Estadual de Defesa Civil do Espírito Santo: Vitória, 2005.

BROLLO, Maria José (coord.). Mapeamento de riscos associados a escorregamentos, inundações, erosão, solapamento, colapso e subsidência do município de Taubaté. Relatório técnico (acesso restrito). 2 v.. São Paulo: Instituto Geológico, 2012.

CÂMARA MUNICIPAL DE TAUBATÉ. Legislação. Disponível em: <http://www.camarataubate.sp.gov.br/Legislacao>. Acesso em 30 jun. 2016.

CARAGUATATUBA. Catástrofe de $1967 . \quad$ Disponível em: <http://www.portal.caraguatatuba.sp.gov.br/caragua_conteudo.php?id=89>. Acesso em: 9 nov. 2014.

CBMDF. Segurança Pública: Defesa Civil. Manual do Curso de Aperfeicoamento de Pracas de 2010. Brasília: CBMDF, 2010. Disponível em <http://dc247.4shared.com/doc/Ougy-quk/preview.html>. Acesso em: 29 mar. 2013. 
COTRIM, Gilberto. História Global: Brasil e Geral. 8. ed. São Paulo: Saraiva, 2005. 608 p.

DOURADO, Francisco; ARRAES, Thiago Coutinho; SILVA, Mariana Fernandes e. O Megadesastre da Região Serrana do Rio de Janeiro: as causas do evento, os mecanismos dos movimentos de massa e a distribuição espacial dos investimentos de reconstrução no pós-desastre. Anuário do Instituto de Geociências - UFRJ, v. 35, n. 2, p. 43-54, 12 mar. 2013. Instituto de Geociências - UFRJ. Disponível em: <http://dx.doi.org/10.11137/2012_2_43_54>. Acesso em: 13 out. 2016.

FOLHA de São Paulo. Há 50 anos: EUA emprestam US\$ 131 milhões para combater seca no Nordeste. Disponível em: <http://www1.folha.uol.com.br/fsp/cotidiano/36842- ha-50-anos.shtml>. Acesso em: 18 jan. 2015.

GAZETA de São Paulo. Defesa Civil realiza oficina da “Operação Verão" em Juquiá. 21 out. 2015. Disponível em: <http://www.gazetasp.com.br/vale-do-ribeira/4559-defesa-civil-realiza-oficina-daoperacao-verao-em-juquia>. Acesso em: 13 out. 2016.

LAKATOS, Eva Maria; MARCONI, Marina de Andrade. Fundamentos de metodologia científica. 7.ed. São Paulo: Atlas, 2012.

LEITE, Eduardo de Oliveira. Monografia jurídica. 3. ed. São Paulo: Revista dos Tribunais, 1997.

MOURA, Emerson Affonso da Costa. As Políticas Públicas Urbanas Brasileiras e a Gestão Democrática: o Controle Social na Efetivação do Direito à Cidade. Revista de Direito da Cidade, v. 8, n. 3, p. 1064-1095, 2 ago. 2016. Universidade do Estado do Rio de Janeiro. Disponível em: <http://http://dx.doi.org/10.12957/rdc.2016.22479>. Acesso em: 23 ago. 2016.

OLIVEIRA, Marcos de. Gerenciamento de Desastres: Sistema de Comando em Operações. Livrotexto do projeto Gerenciamento de Desastres. Florianópolis: UFSC, 2009. 74 p.

PORTO ALEGRE. Histórico de Enchentes em Porto Alegre. Disponível em: $<$ http://Iproweb.procempa.com.br/pmpa/prefpoa/metroclima/default.php? reg=7\&p_secao=12>. Acesso em: 11 nov. 2014.

SÃO PAULO. Defesa Civil realiza Oficina Preparatória para a Operação Estiagem em São José do Rio Preto. 182016.2 maio $20 m$ : <http://www.saopaulo.sp.gov.br/spnoticias/salaimprensa/home/imprensa_lenoticia. .php?id=24590 9>. Acesso em: 13 out. 2016.

SEADE. Informações dos Municípios Paulistas: Taubaté. Disponível em: <http://www.imp.seade.gov.br/frontend/\#/perfil>. Acesso em: 23 abr. 2016.

O estado dos municípios 2010-2012: Índice Paulista de Responsabilidade Social. São Paulo: SEADE, 2015. Disponível em: <http://indicesilp.al.sp.gov.br/view/pdf/iprs/IPRS_2014_V1_Sintese.pdf>. Acesso em 23 abr. 2016.

TAUBATÉ. Lei no 2.066, de 29 de novembro de 1983. Dispõe sobre a instituição da Campanha Permanente de Defesa Civil. Disponível em: $<$ http://www.camarataubate.sp.gov.br/abrir_arquivo.aspx/Lei_2066_1983?cdLocal=5\&arquivo $=\{42$ EB52CC-722C-6EE7-E7B0-0A5D5A7DABBE\}.pdf>. Acesso em: 30 jun. 2016. 
Lei Orgânica do Município de Taubaté. Disponível em: <http://www.camarataubate.sp.gov.br/abrir_arquivo.aspx/Lei_Organica_do_Municipio_de_Taubat e_1_1990?cdLocal $=5$ \&arquivo $=\{4$ B3E30EC-25E2-CBOA-

37CCD7EED7DD84BD\}.pdf\#search=defesa\%20civil>. Acesso em: 30 jun. 2016.

TAUBATÉ. Decreto no 7.286, de 19 de abril de 1993. Reorganiza e regulamenta o Sistema Municipal de Defesa Civil. Taubaté: Prefeitura de Taubaté, 1993.

Lei no 5.144, de 12 de janeiro de 2016. Cria a Coordenadoria Municipal de Proteção e Defesa Civil - COORDEC do Município de Taubaté - SP, cria o Conselho Municipal de Proteção e de Defesa Civil - COMDEC, e cria o Fundo Municipal de Proteção e Defesa Civil - FUMPDEC do Município de Taubaté - SP e dá outras providências. Disponível em: <http://www.taubate.sp.gov.br/anexos/leis/2016/5144.pdf>. Acesso em: 20 maio 2016.

TEMPO AGORA. SP: Defesa Civil inicia oficinas para Operação Verão 2015/2016. 2 out. 2015. Disponível em: <http://www.tempoagora.com.br/dia-a-dia/defesa-civil-estado-de-sao-paulo-iniciaoficinas-para-operacao-verao-20152016/>. Acesso em: 13 out. 2016.

UFSC. Universidade Federal de Santa Catarina. Centro Universitário de Pesquisa e Estudos sobre Desastres. Capacitação básica em Defesa Civil. 3. ed. Florianópolis: UFSC, 2013. 122 p.

Universidade Federal de Santa Catarina. Centro Universitário de Pesquisa e Estudos sobre Desastres. Capacitação básica em Defesa Civil. 5. ed. rev. ampl. atual. Florianópolis: UFSC, 2014. 160 p.

UN. A/RES/44/236. International Decade for Natural Disaster Reduction. Nova lorque: UN, 1989. Disponível em: <http://www.un.org/documents/ga/res/44/a44r236.htm>. Acesso em: 18 jan. 2015.

UNISDR. International Strategy for Disaster Reduction. Disponível em: $<$ http://www.unisdr.org/whowe-are/international-strategy-for-disaster-reduction>. Acesso em: 25 mar. 2013.

Marco de Ação de Hyogo 2005-2015: Aumento da resiliencia das nacões e das comunidades frente aos desastres. Traducão por: Luís Felipe Lopes de Lima Lins. Genebra: UNISDR, 2007. 6 p.

VEIGA JUNIOR, João Carlos Valentim. Proteção e Defesa Civil: uma análise dos órgãos municipais da Região Metropolitana do Vale do Paraíba. 2015. 61 f. Trabalho de conclusão de curso (Graduação) - Curso de Direito, Centro Universitário Salesiano de São Paulo, Lorena, 2015.

Trabalho enviado em 23 de agosto de 2016.

Aceito em 14 de outubro de 2016. 